\title{
Pyogenic Granuloma and Arteriovenous Malformation
}

الورم الحبيبي القيحي والتشوه الشرياني

غابرييل رودريغز، بالاجي جاياسانكار، كريشنا جانومبالي
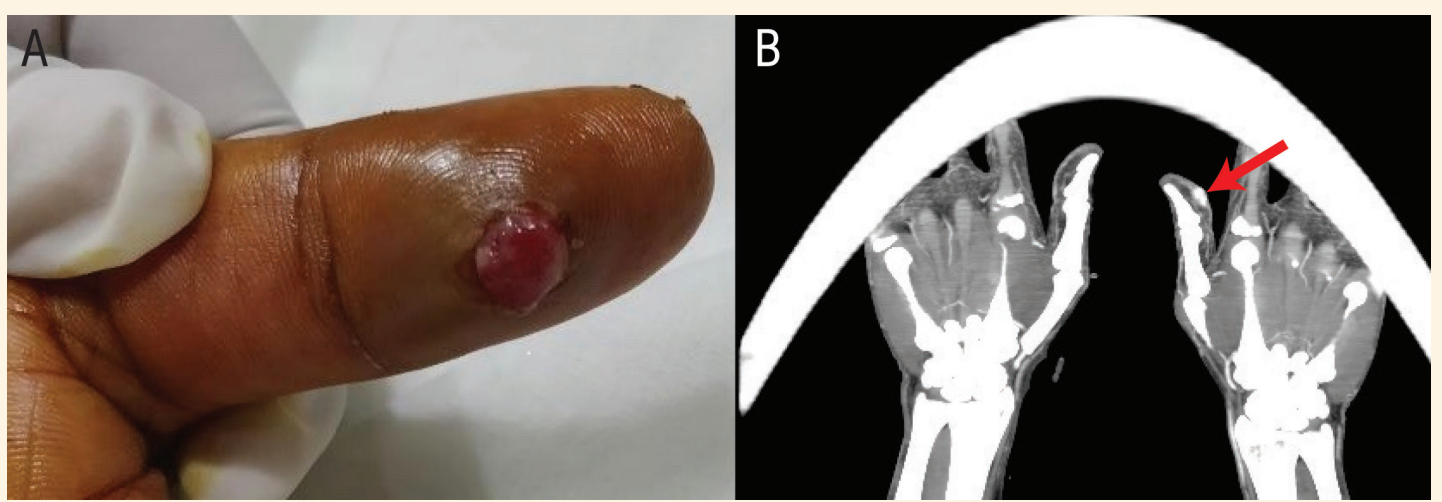

Figure 1: A: Photograph of the distal phalanx of the left thumb of a 44-year-old male patient showing a noduloulcerative lesion. B: Computed tomography angiogram showing a tumour blush (arrow).

A 44-YEAR-OLD MALE PATIENT PRESENTED TO the Kasturba Medical College Hospital, Manipal, India, in 2018 with a two-month history of a repeatedly bleeding, non-healing nodule over the tip of his left thumb following minor trauma with a sharp object during his work as a barber. He had been treated on an outpatient basis at various clinics without success. Evaluation revealed a nodular growth of $0.5 \times 0.5 \mathrm{~cm}$ over the distal phalanx of his left thumb [Figure 1A]. The nodule continued to bleed and required a continuous pressure dressing to control the flow. On occlusion of the left radial artery, the bleeding temporarily receded. With a clinical diagnosis of a post-traumatic arteriovenous (AV) malformation, a computed tomography angiogram of the left upper limb revealed an AV fistula at the site of the distal phalanx of the left thumb with feeding vessels from the left radial artery [Figure 1B]. The lesion was excised and haemostasis was achieved [Figure 2A]. Histopathology revealed lobulated proliferation of capillary sized vessels, inflammatory cells in a loose and oedematous stroma with findings indicative of a pyogenic granuloma (PG) [Figure 2B].

\section{Comment}

PG is often regarded as a hyperplastic process and is known to grow in response to trauma, hormonal factors and usually presents with pouting granulation tissue. However, histologically they are lobular capillary haemangiomas. ${ }^{1}$ Clinically, they mimic lesions such as vascular malformations, haemangiomas, amelanotic melanomas (AMM), dermal nevi and basal cell carcinomas. ${ }^{2,3}$ These lesions should be histopathologically distinguished from each other, especially as AMM accounts for a small proportion of all melanomas and poses a risk of delayed diagnosis and poor prognosis. An interesting variant of PG or lobular capillary haemangioma involving the hand is the intravenous PG which develops within the lumen of the vein. However, in this variant the classical lobular pattern may not be as pronounced as in their extravascular counterparts. ${ }^{1}$ Treatment modalities vary and range from topical application of $1 \%$ propranolol to laser coagulation and surgical excision depending on the site and location. ${ }^{4}$ 


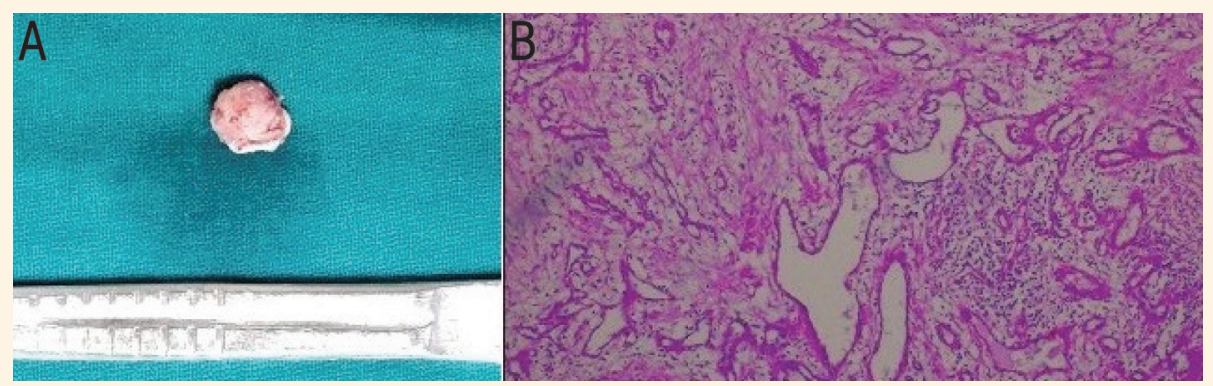

Figure 2: A: Photograph of the excised specimen from the left thumb of a 44-year-old male patient. B: Haematoxylin and eosin stain at $\times 40$ magnification showing lobulated proliferation of capillary sized vessels and inflammatory cells in a loose and oedematous stroma.

AV fistulas following a low velocity penetrating injury is well known and the associated clinical signs could be misleading, which might not indicate a clear diagnosis. ${ }^{4}$ Despite the various treatment modalities described for AV fistula (e.g. ligation of feeders, embolisation and injection of sclerosing agents), an early surgical excision is recommended to alleviate local and systemic complications. ${ }^{3,5}$

This case highlights that both these conditions may mimic each other especially in small wounds following a trauma. It is prudent to differentiate between a relatively benign PG versus its sinistral counterpart, an AV fistula.

\section{References}

1. Pantanowitz L, Duke WH. Intravascular lesions of the hand. Diagn Pathol 2008; 3:24. https://doi.org/10.1186/1746-1596-3-24.

2. Baroni A, Piccolo V. Images in clinical medicine. Red melanoma. N Engl J Med 2013; 368:1536. https://doi.org/10.1056/NEJMic m1207155.

3. Colletti G, Valassina D, Bertossi D, Melchiorre F, Vercellio G, Brusati R. Contemporary management of vascular malformations. J Oral Maxillofac Surg 2014; 72:510-28. https://doi.org/10.1 016/j.joms.2013.08.008.

4. Longhurst WD, Khachemoune A. An unknown mass: The differential diagnosis of digit tumors. Int J Dermatol 2015; 54:1214-25. https://doi.org/10.1111/ijd.12980.

5. Wollina U, Langner D, França K, Gianfaldoni S, Lotti T, Tchernev G. Pyogenic granuloma - A common benign vascular tumor with variable clinical presentation: New findings and treatment options. Open Access Maced J Med Sci 2017; 5:423-6. https://doi.org/10.3889/oamjms.2017.111. 